\title{
It is not just about surgery versus stereotactic ablative radiotherapy, it is about curing as many patients with lung cancer as possible
}

\author{
Alessandro Brunelli, MD
}

\footnotetext{
From the Department of Thoracic Surgery, St James's University Hospital, Leeds Teaching Hospital NHS Trust, Leeds, United Kingdom.

No funding was used for this work

Disclosures: Author has nothing to disclose with regard to commercial support.

Received for publication March 30, 2018; accepted for publication April 5, 2018; available ahead of print May 10, 2018.

Address for reprints: Alessandro Brunelli, MD, Department of Thoracic Surgery, St. James's University Hospital, Bexley Wing, Beckett St, Leeds LS9 7TF, United Kingdom (E-mail: alexit_2000@yahoo.com).

J Thorac Cardiovasc Surg 2018;156:1247-8

$0022-5223 / \$ 36.00$

Copyright (C) 2018 by The American Association for Thoracic Surgery

https://doi.org/10.1016/j.jtcvs.2018.04.005
}

The article by Engelhardt and colleagues ${ }^{1}$ published in this issue of the Journal is an important contribution, reporting as it does the national trends of curative treatment of earlystage non-small cell cancer (NSCLC) in the United States from 2004 to 2013. Engelhardt and colleagues ${ }^{1}$ were able to show a progressive reduction in the proportion of patients radically treated with surgery, accompanied by a parallel increase in the proportion of those treated with stereotactic ablative radiotherapy (SABR).

Engelhardt and colleagues ${ }^{1}$ put a great emphasis on the reduction of surgical rates relative to the increase in radiation therapy. In my opinion, however, there is an equally important figure that deserves to be highlighted.

The absolute numbers of patients reported in the tables of Engelhardt and colleagues ${ }^{1}$ show a progressive increase in patients with early-stage NSCLC treated during the study period. In the years 2004 and 2005, there were 33,962

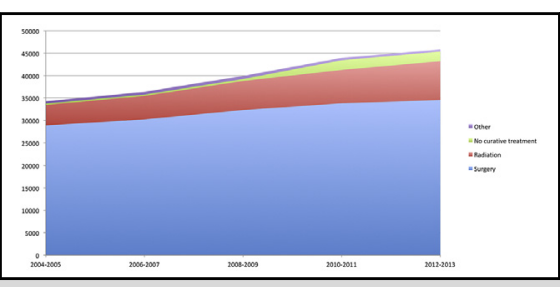

Patients with early-stage lung cancer treated with various modalities, 2004-2013.

\section{Central Message}

Refinements in curative surgical and nonsurgical treatments allow more and more patients with early-stage lung cancer to be treated in the face of an increasingly comorbid and elderly population.

See Article page 1233 .

patients receiving any type of curative treatment. This number increased to 43,678 patients $(+29 \%)$ in the years 2012 and 2013. This increase occurred for both surgery $(+5663$ patients) and SABR (+4107 patients; Figure 1). In addition, in the last 3 years of the study period (from 2011 to 2013), the number of patients treated with surgery $(17,075-17,311)$ or SABR (3890-4465) remained substantially stable. Another important finding is the large increase in the

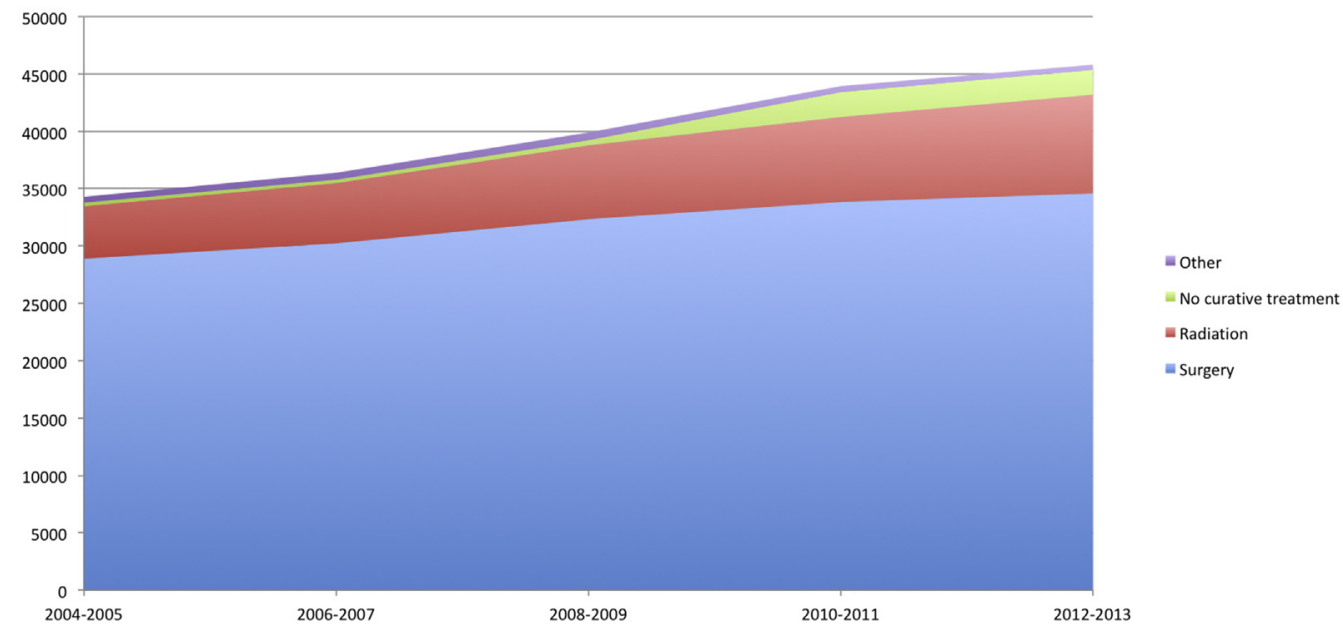

FIGURE 1. Stacked area chart showing the absolute numbers of patients with early-stage lung cancer treated with various modalities from 2004 to 2013. 
number of patients receiving no curative treatment from 2010. Approximately 1000 patients per year did not receive any curative treatment in the last 4 years of the study.

Overall, these results may reflect a progressive change in the case mix of the patients presenting with earlystage NSCLC. With the increase in early detection of NSCLC, there may be a parallel increase in the number of older patients with more underlying comorbidities and greater functional compromise. These latter patients, who are not surgical candidates, may have contributed to the increased numbers of SABR or noncurative treatments. Still, the number of patients receiving surgery has increased.

In this context, the missing pieces of information in this study are the overall and cancer specific survivals. Engelhardt and colleagues deliberately refrained to perform a survival analysis because of the impossibility of controlling for many confounding factors, such as a patient's comorbid conditions and suitability for treatment, which may have influenced the prognosis. I completely agree that big data analyses like this one are often plagued by the lack of specific critical variables. For the same reason, however, the trend analysis presented by Engelhardt and colleagues ${ }^{1}$ in this study may have been influenced by similar unaccounted factors. In a more global interpretation of the results, it is not important whether surgery was more effective than SABR but rather whether there was an overall improvement in survival in the entire cohort of patients with early-stage lung cancer receiving treatment with curative intent. We now have more management options to treat radically even an increasingly elderly and comorbid population presenting with early-stage lung cancer. More and more patients will be able to be treated with one or the other modality, and it is to be hoped that future prospective studies will be able to define better the proper indications for SABR relative to surgery. Does this translate to a better overall survival of the population with lung cancer?

\section{Reference}

1. Engelhardt KE, Feinglass JM, DeCamp MM, Bilimoria KY, Odell DD. Treatment trends in early stage lung cancer in the United States, 2004-2013: a time-trend analysis of the national cancer data base. J Thorac Cardiovasc Surg. 2018;156: $1233-46$. 